\title{
Strong Kelvin wave activity observed during the westerly phase of QBO - a case study
}

\author{
U. Das and C. J. Pan \\ Institute of Space Science, National Central University, Jhongli-32001, Taiwan \\ Correspondence to: C. J. Pan (cjpan@jupiter.ss.ncu.edu.tw) \\ Received: 28 December 2012 - Revised: 22 February 2013 - Accepted: 27 February 2013 - Published: 4 April 2013
}

\begin{abstract}
Temperature data from Global Positioning System based Radio Occultation (GPS RO) soundings of the Formosa Satellite mission 3/Constellation Observing System for Meteorology, Ionosphere and Climate (FORMOSAT3/COSMIC or F-3/C) micro satellites have been investigated in detail to study the Kelvin wave (KW) properties during September 2008 to February 2009 using the two-dimensional Fourier transform. It is observed that there was strong KW activity during November and December 2008; large wave amplitudes are observed from above the tropopause to $40 \mathrm{~km}$ - the data limit of F-3/C. KW of wavenumbers E1 and E2 with time periods 7.5 and 13 days, dominated during this period and the vertical wavelengths of these waves varied from 12 to $18 \mathrm{~km}$. This event is very interesting as the QBO during this period was westerly in the lower stratosphere (up to $\sim 26 \mathrm{~km}$ ) and easterly above, whereas, climatological studies show that KW get attenuated during westerlies and their amplitudes maximise during easterlies and westerly shears. In the present study, however, the eastward propagating $\mathrm{KW}$ crossed the westerly lower stratosphere as the vertical extent of the westerly wind regime was less than the vertical wavelengths of the KW. The waves might have deposited eastward momentum in the upper stratosphere at $26-40 \mathrm{~km}$, thereby reducing the magnitude of the easterly wind by as much as $10 \mathrm{~m} \mathrm{~s}^{-1}$. The outgoing long wave radiation (OLR) is also investigated and it is found that these $\mathrm{KW}$ are produced due to deep convections in the lower atmosphere.
\end{abstract}

Keywords. Meteorology and atmospheric dynamics (Convective processes; Middle atmosphere dynamics; Waves and tides)

\section{Introduction}

Kelvin waves $(\mathrm{KW})$ play a very important role in the dynamics of the equatorial middle atmosphere. These eastward propagating planetary scale waves carry eastward momentum upwards and are damped by various processes like radiative cooling, small scale turbulence and critical level interactions. As the waves are damped they lose momentum and accelerate the westerly mean flow of the quasi-biennial oscillation (QBO). The vertical component of the group velocity decreases with time and the $\mathrm{KW}$ are damped at lower heights causing the westerly zone to descend (Holton and Lindzen, 1972). In addition to KW, Rossby-gravity waves, inertia-gravity waves and small-scale gravity waves propagating vertically upward are all responsible for driving the QBO (Dunkerton, 1997; Baldwin et al., 2001; Kawatani et al., 2010). However, quantification of the contributions of each of the different waves to the dynamics of middle atmosphere is still very uncertain. Ern and Preusse (2009) found that the contribution of the equatorial $\mathrm{KW}$ to the reversal from stratospheric easterlies to westerlies is only $30-50 \%$.

$\mathrm{KW}$ in the atmosphere were first suggested by Matsuno (1966); and Holton and Lindzen (1968) discussed them specifically as a special solution to linearised equations for an equatorial $\beta$-plane. Later, Wallace and Kousky (1968) showed observational evidences in the tropical stratospheric zonal winds and temperature using radiosonde data. The phase propagation was eastward and downward and the wave motion was in the zonal and vertical directions only. There was no meridional component observed. The average period of the waves was 15 days and the amplitude was $8-12 \mathrm{~m} \mathrm{~s}^{-1}$ in the zonal wind and 3-5 $\mathrm{K}$ in temperature. Also, the temperature was found to lead the zonal wind by $1 / 4$ cycle. Many climatological and campaign-based studies followed 
using data from radiosondes (Shiotani and Horinouchi, 1993; Tsuda et al., 1994; Holton et al., 2001), ozonosondes (Fujiwara et al., 1998), radars (Tsuda et al., 2002), etc., which were confined to a particular location. Later, $\mathrm{KW}$ and their properties were investigated using satellite measurements in the middle atmosphere (Salby et al., 1984; Hitchman and Leovy, 1988; Canziani et al., 1994; Shiotani et al., 1997; Canziani and Holton, 1998; Mote et al., 2002; Sridharan et al., 2006; Ern et al., 2008) and mesosphere and lower thermosphere (Hirota, 1978; Lieberman and Riggin, 1997; Forbes et al., 2009). Most recently, temperatures measured using the Global Positioning System based Radio Occultation (GPS RO) technique by GPS/MET, SAC-C, CHAMP (Tsai et al., 2004; Tsuda et al., 2006; Venkat Ratnam et al., 2006), and Formosa Satellite mission 3/Constellation Observing System for Meteorology, Ionosphere and Climate (FORMOSAT-3/COSMIC or F-3/C) were also used to investigate the KW (Alexander et al., 2008; Pan et al., 2011). Simultaneously, many theoretical and modelling studies also followed to investigate the various equatorial waves (Kawatani et al., 2009).

KW are also known to affect the dynamics, cloud physics and transport around the tropical tropopause layer (Fueglistaler et al., 2009). They exhibit maximum amplitude and are quasi-stationary near the tropical tropopause and in the lower stratosphere they are found to exhibit regular eastward propagation (Randel and $\mathrm{Wu}, 2005$ ). Suzuki et al. (2010) examined the lifetimes and longitudinal variability of the equatorial kelvin waves around the tropical tropopause region. KW also play an important role in stratospheretroposphere exchange of trace constituents (Tsuda et al., 1994; Fujiwara et al., 1998).

Kelvin waves with periods ranging from 10 to 20 days and 6 to 10 days are classified as slow and fast waves, respectively. The vertical wavelengths of these waves are small and are confined to the middle atmosphere below the stratopause (Salby et al., 1984). However, waves of very small periods ranging from 3 to 5 days are termed as ultra-fast $\mathrm{KW}$ and play a very important role in the vertical coupling of the atmosphere (Forbes, 2000). These waves have very large vertical wavelengths and are capable of propagating through the stratosphere and reach mesosphere and lower thermosphere or higher (Hirota, 1978, 1979; Lieberman and Riggin, 1997; Forbes et al., 2009) and can significantly perturb the thermospheric neutral densities and total electron content (Chang et al., 2010). Ultra-fast KW were observed in meteor measurements and Thermosphere Ionosphere Mesosphere Energetics and Dynamics/Sounding of the Atmosphere using Broadband Emission Radiometry (TIMED/SABER) temperatures in the mesosphere and lower thermosphere and simultaneously in the critical frequency foF2, suggesting the propagation of the waves to ionospheric heights (Takahashi et al., 2007).

Temperature data from GPS RO soundings of the F-3/C micro satellites has been investigated by Pan et al. (2011) in detail to study the KW properties during August 2006 to August 2009 in the lower stratosphere. A statistical analysis was done and the general horizontal characteristics and climatology of the Kelvin waves were presented. The study also concluded that the amplitudes of the Kelvin waves in the stratosphere were high during the easterly phase of the QBO and maximum when the easterlies changed to westerlies, consistent with earlier studies (e.g., Venkat Ratnam et al., 2006). However, during this study, strong KW activity was observed during November and December 2008 and the event is very interesting as the zonal winds in the lower stratosphere were westerlies. This is in contrast to the known climatology of the Kelvin waves with respect to the mean zonal wind. In the current study, this particular event, and its effects on the zonal winds are investigated in detail. The vertical properties of the kelvin waves are also investigated, which has not been done earlier by Pan et al. (2011). The two-dimensional fast Fourier transform (2D-FFT; Hayashi, 1982) is used to spectrally analyse the temperature fluctuation data to obtain the dominant wavenumbers, periods and vertical wavelengths of the KW during this event, and also before and after the event. Three 64-day periods are, thus, chosen as follows - (a) 29 August 2008 to 31 October 2008 (September and October 2008), (b) 28 October 2008 to 30 December 2008 (November and December 2008), (c) 27 December 2008 to 28 February 2009 (January and February 2009), hereafter referred to as P1, P2, and P3.

\section{Data and analysis}

Six F-3/C micro satellites were launched into a circular, $72^{\circ}$ inclination orbit at an altitude of $512 \mathrm{~km}$ on 15 April 2006. The mission goal was to deploy the six satellites into six orbit planes at $800 \mathrm{~km}$ with a $30^{\circ}$ separation for evenly distributed global coverage, which has been successfully achieved. It is the first constellation of satellites for monitoring global weather and ionospheric electron density distribution using the GPS RO technique. For the lower atmosphere, COSMIC provides the refractivity profiles, which are processed real-time by the COSMIC Data Analysis and Archive Center (CDAAC) at the University Corporation for Atmospheric Research (UCAR) to give profiles of temperature and water vapour. Further details regarding the spacecraft constellation system can be obtained from Fong et al. (2009). COSMIC temperature data in the equatorial stratosphere region from September 2008 to February 2009 is analysed in the present study to investigate the properties of atmospheric KW in relation to the tropical zonal wind. KW have maximum amplitude over the equator and so the investigations are confined to the equatorial belt from $10^{\circ} \mathrm{N}-10^{\circ} \mathrm{S}$. An added advantage of this is that the contamination by waves from other latitudinal regions is also minimised. Figure 1 shows a histogram of the number of profiles that were available from all the six COSMIC satellites on each day with an average of 118 


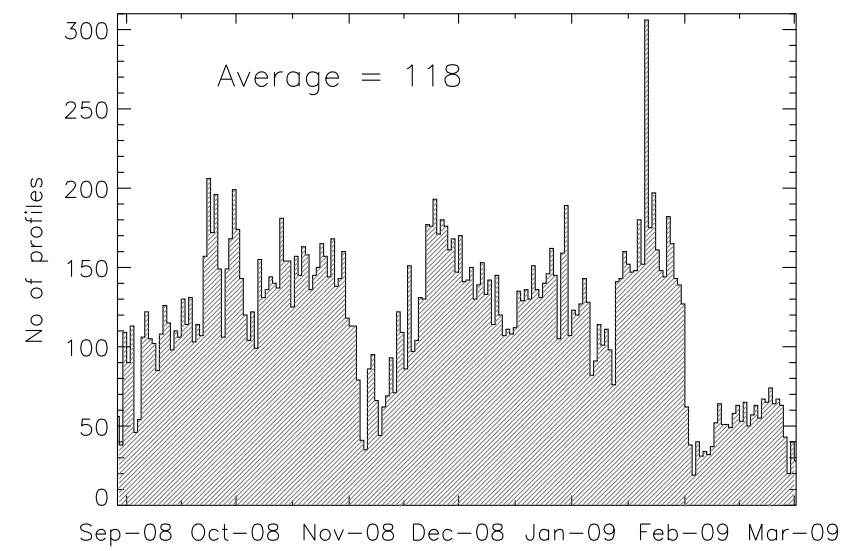

Fig. 1. Number of profiles available from the FORMOSAT$3 / \mathrm{COSMIC}$ observations in $10^{\circ} \mathrm{S}-10^{\circ} \mathrm{N}$ latitude region on each day during September 2008 to February 2009. The average number of profiles per day is 118 .

profiles per day. This data availability is more than a magnitude higher than the amount of data available from earlier satellite instruments like CHAMP and SAC-C, which is only 10-13 profiles per day (Tsai et al., 2004).

Data used in the present study comprises of COSMIC version 2010.2640 "wet" temperature profiles from surface to $40 \mathrm{~km}$ altitude. Water vapour information is included in retrieving the "wet" temperature from COSMIC observations, and it shows significant differences from the "dry" temperature only at altitudes below $10 \mathrm{~km}$. In the upper troposphere and stratosphere, both "wet" and "dry" temperature profiles are similar. Rao et al. (2009) performed a validation study of the COSMIC data over Gadanki $\left(13.48^{\circ} \mathrm{N}, 79.2^{\circ} \mathrm{E}\right)$, a tropical region. A very good comparison was found with the radiosonde temperature observations with a mean difference of less than $1 \mathrm{~K}$ from 10 to $27 \mathrm{~km}$. Between 30 and $40 \mathrm{~km}$, a large difference of $8 \mathrm{~K}$ was found when compared to lidar observations. Hayashi et al. (2009) also showed good comparisons between COSMIC RO and the radiosonde refractivity profiles with 1-2\% mean difference. Kishore et al. (2009) performed a validation study using the operational stratospheric analyses including the National Centers for Environmental Prediction reanalysis (NCEP), the Japanese 25year Reanalysis (JRA-25) and the United Kingdom Met Office (UKMO) datasets. Good agreement was observed between the COSMIC and the various reanalysis outputs, with mean global differences and differences in the height range from 8 to $30 \mathrm{~km}$ being less than $1 \mathrm{~K}$. Largest deviations were observed spatially over polar latitudes and altitude-wise at the tropical tropopause with differences being $2-4 \mathrm{~K}$. In the present study, we are investigating the COSMIC temperatures over the equatorial region above the tropopause layer and, hence, the above validation studies show that in this region of interest COSMIC data is of very good quality.

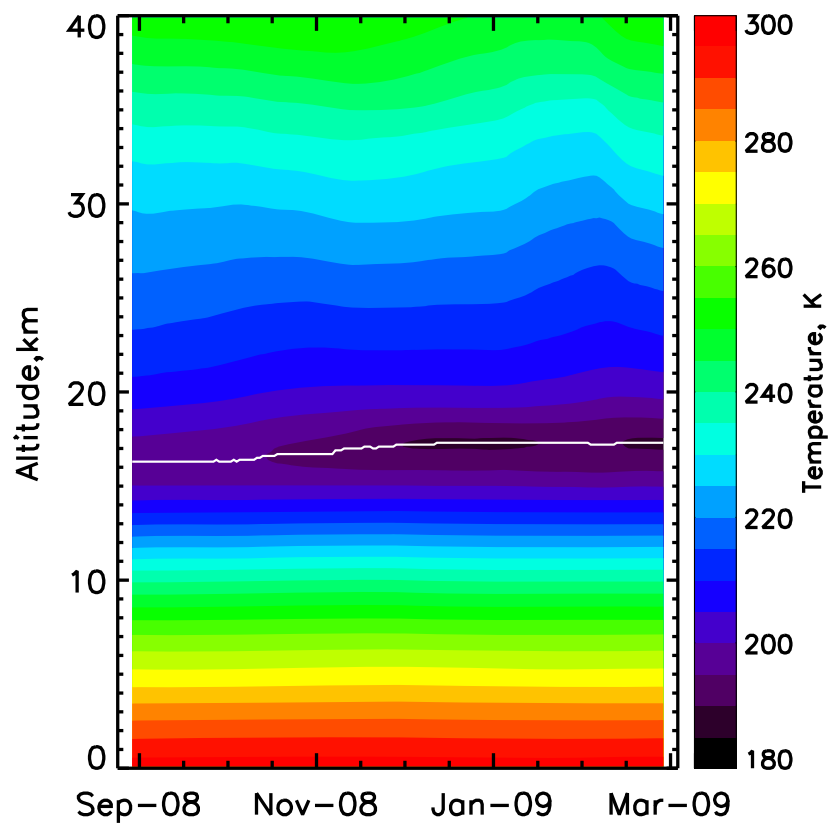

Fig. 2. Variation of 31-day median temperature during September 2008 to February 2009. The white dashed line at $\sim 16-17 \mathrm{~km}$ shows the tropopause.

Each temperature profile is interpolated with $0.1 \mathrm{~km}$ spacing from surface to $40 \mathrm{~km}$ and gridded into $10^{\circ}$ longitude sectors. Mean temperature profile in each sector for the day is obtained and 31-day (15 before and 15 later) median profile is then subtracted to obtain the temperature fluctuations. It may be noted that the time of observations in a given sector during a day may vary; however, as we are interested in the planetary wave activity, it is assumed that this averaging will have little effect on the results. Any gaps thereof are filled by linear interpolation at each altitude. Figure 2 shows the median temperature variation during September 2008 to February 2009. The tropopause, shown by a white line, is at $\sim 16-17 \mathrm{~km}$ altitude. The tropopause temperature during September 2008 was $196 \mathrm{~K}$ and decreased to $190 \mathrm{~K}$ during November.

Temperature fluctuations computed using this procedure are shown in Fig. 3 during the period of interest at $20 \mathrm{~km}$. Observe the very large scale structures, propagating eastward at all times. Particularly during November and December, the amplitudes of the temperature fluctuations are much larger ( \pm 3 to $6 \mathrm{~K})$. Figure 4 shows the temperature fluctuations on 31 August 2008 and 16 November 2008, as functions of altitude and longitude. Observe the large scale wave structures on both days and the vertical tilt of these waves. Fluctuations on consecutive days show downward propagation of the phase of the wave indicating upward energy and momentum transport. The amplitudes are much higher on 16 November, indicating strong wave activity compared to those on $31 \mathrm{Au}-$ gust. Thus, Figs. 3 and 4 establish that the large scale features 


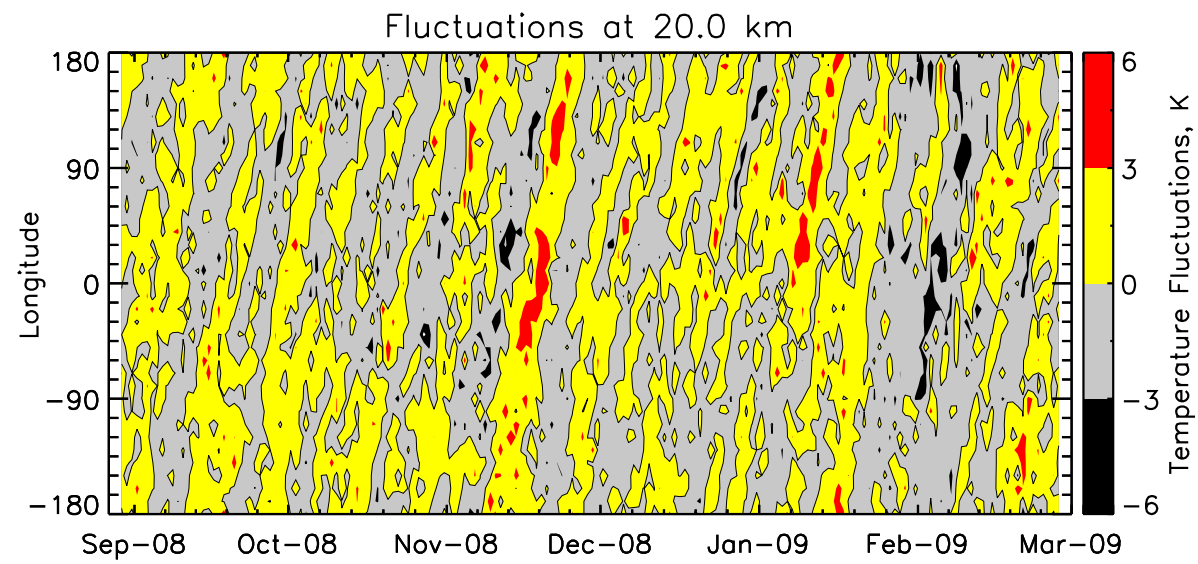

Fig. 3. Temperature fluctuations at $20 \mathrm{~km}$ during the period of interest from September 2008 to February 2009. Observe the eastward propagating large scale structures.

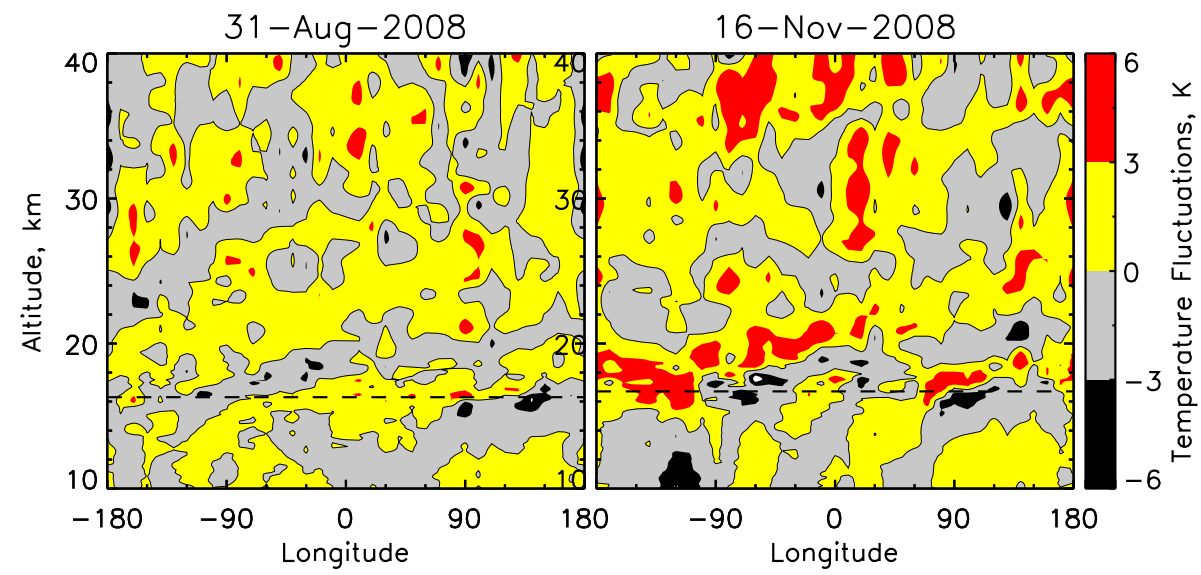

Fig. 4. Temperature fluctuations on 31 August 2008 and 16 November 2008 showing the vertical structure of the temperature fluctuations. Observe the large amplitudes on 16 November.

observed in the temperature fluctuations have the characteristics and are, therefore, the $\mathrm{KW}$, i.e., eastward propagating waves with downward phase propagation.

2D-FFT is applied to the temperature fluctuations to quantify these properties of the KW. 2D-FFT is a very good method to extract wave characteristics in a parameter, which is a function of two variables (Hayashi, 1982). In the present study, we are using the 2D-FFT on the temperature fluctuations data that is a function of longitude and time. The result is a 2-D Fourier spectrum that is a function of wavenumber and frequency/period and the 2-D Fourier power (2D-FP) is represented as a wavenumber-period-power distribution. The ends along the longitude are tapered using a Hanning window as 2D-FFT assumes the data to be cyclic in space and limited in time. This method in literature is called the space time spectral analysis technique (Hayashi, 1982; Wheeler and Kiladis, 1999). However, we prefer to call this as 2D-FFT in the current study, as we have also used this technique on the temperature fluctuations data on each day, which is a function of longitude and altitude, to obtain the 2-D Fourier spectrum represented as a wavenumber-vertical wavelength-power distribution.

All individual spectra are averaged and repeatedly smoothed following the procedure described by Wheeler and Kiladis (1999) to obtain the background noise spectrum, which is red in nature. The exercise is done separately for the wavenumber-period-power distribution and wavenumber-vertical wavelength-power distribution. Each individual spectrum is then divided with the noise spectrum and the $95 \%$ confidence levels are also identified to pick the statistically significant peaks.

\section{Results and discussion}

2D-FFT is applied to the temperature fluctuation data at each altitude as shown in Fig. 3 during the three periods of interest, P1, P2 and P3 and also to the temperature fluctuation data on each day as shown in Fig. 4. The top panel of 
Fig. 5 shows the 2D-FP for the period P2 at altitude $20 \mathrm{~km}$ as a function of period and wavenumber (wavenumber-periodpower distribution) divided by the background noise spectrum. Thick black contours of confidence levels $95 \%$ are also plotted to show the statistical significance of the spectral peaks. Positive wavenumbers correspond to eastward propagating waves and negative wavenumbers correspond to westward propagating waves. In this spectrum, the eastward propagating waves with wavenumbers 1 and 2 are dominating and are, hereafter, referred to as E1 and E2 (E for Eastward). E1 has a period of $\sim 15$ days and E2 has a period of 8 days. These dominant periods are marked by dotted lines in the figure to aid the eye. The bottom panel of Fig. 5 shows the 2D-FP on 16 November 2008 as a function of wavenumber and vertical wavelength (wavenumber-vertical wavelengthpower distribution). The dominant features are the E1 and E2 components, with vertical wavelengths of 6 and $9 \mathrm{~km}$, respectively, marked by the dotted lines. This figure shows that at a given altitude or a given day, not one particular $\mathrm{KW}$, but, a packet of $\mathrm{KW}$ are propagating in the upper troposphere and the lower stratosphere region. To obtain the larger picture, composites of 2D-FP from the wavenumberperiod-power distribution at all altitudes are shown, at both wavenumbers (rows) and during the three periods of interest (columns) in Fig. 6. The colour code is same as in Fig. 5 and the thick black contours indicate the $95 \%$ confidence level. The dominant periods during P1 are 15 days at E1. During P2, the dominant periods are 13 and 7.5 days at E1 and E2, respectively, and during P3, the dominant period is 11 days at E1. Here also, these dominant periods are marked by dotted lines in the figure to aid the eye. Observe that during P2, waves at E2 are enhanced in the lower stratosphere. Further, the powers at E1 are higher from $\sim 19$ to $26 \mathrm{~km}$ and become smaller from $\sim 26$ to $34 \mathrm{~km}$. Thereafter, above $34 \mathrm{~km}$, the powers increase once again. However, during P3, the power of $\mathrm{E} 1$ is high and almost constant at all altitudes. During P1, the power at E1 is moderate and at E2, it is mostly concentrated around $20 \mathrm{~km}$ only. Similarly, to investigate the dominant vertical wavelengths, composites of wavenumbervertical wavelength-power distributions at wavenumbers E1 and E2 are shown in Fig. 7. The colour code in this figure is also the same as in Fig. 5 and the thick black contours indicate the $95 \%$ confidence level. During P1, the powers are moderate and occasionally peak at $12 \mathrm{~km}$ for E1; during P2 and $\mathrm{P} 3$, the statistically significant vertical wavelengths range from 12 to $18 \mathrm{~km}$ at E1 and E2 as shown by the dotted lines. This shows that during P2 and P3, there was an increase in the Kelvin wave activity and, more importantly, the vertical wavelengths of the KWs were large.

The periods and vertical wavelengths of the KW observed in the present study are consistent with earlier observations. Table 1 lists the properties of KW, viz., period and mode of observations, wavenumber, period and vertical wavelength, observed in a few of the earlier studies from literature (Wallace and Kousky, 1968; Salby et al., 1984; Canziani et al.,

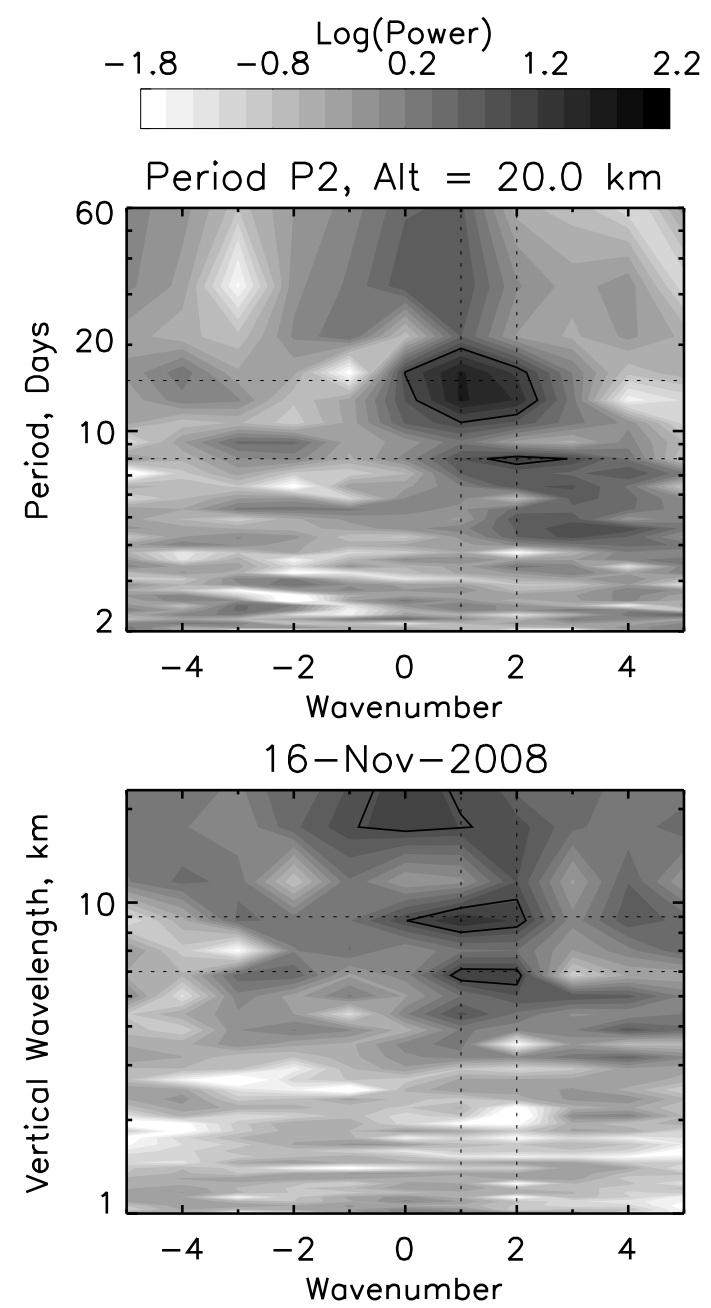

Fig. 5. Top: Two-dimensional Fourier power spectrum of the temperature fluctuations at $20 \mathrm{~km}$ during November-December 2008 (wavenumber-period-power distribution) divided by the background noise spectrum. Wavenumbers 1 and 2 at periods 15 and 8 days, respectively, are dominating. Bottom: Two-dimensional Fourier power spectrum of the temperature fluctuations on 16 November 2008 (wavenumber-vertical wavelength-power distribution) divided by the background noise spectrum. At wavenumbers 1 and 2 the dominant vertical wavelengths are 6 and $9 \mathrm{~km}$. The thick black contours in both panels show the $95 \%$ confidence levels.

1994; Shiotani et al., 1997; Holton et al., 2001; Mote et al., 2002; Sridharan et al., 2006; Tsuda et al., 2006; Venkat Ratnam et al., 2006; Pan et al., 2011). The dominant wavenumbers are 1 and 2 and the periods and vertical wavelengths of the KW vary over wide ranges. Importantly, note that when the waves are fast the vertical wavelengths are larger and vice versa. Thus, the fast waves can propagate to higher altitudes compared to the slow waves (Hirota, 1978, 1979; Salby et al., 1984; Lieberman and Riggin, 1997; Forbes, 2000; Forbes et al., 2009; Chang et al., 2010). 

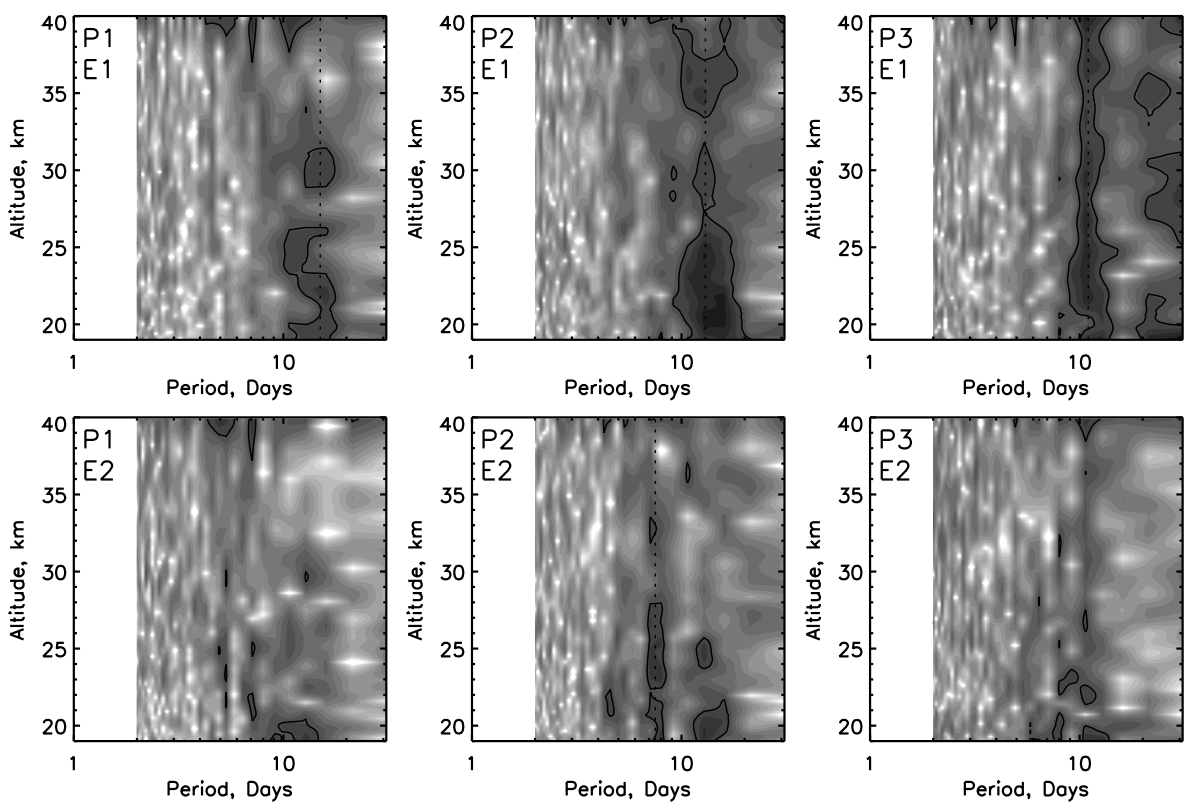

Fig. 6. Two-dimensional Fourier power during the three periods of interest (columns) at wavenumbers 1 and 2 (rows) from the wavenumberperiod-power distribution divided by the background noise spectrum. The thick black contours show the $95 \%$ confidence levels. The colour code is same as in Fig. 5.

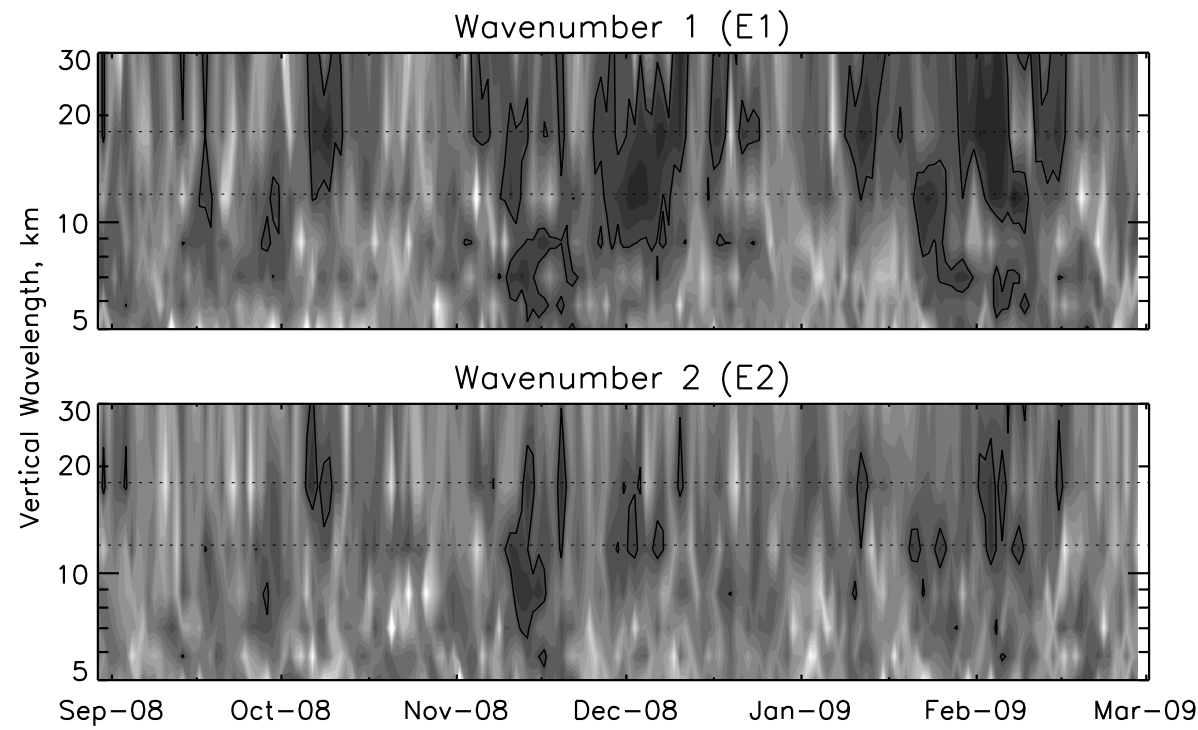

Fig. 7. Two-dimensional Fourier power at both wavenumbers from the wavenumber-vertical wavelength-power distribution during the period of interest. The thick black contours show the $95 \%$ confidence levels. The colour code is same as in Fig. 5.

\subsection{Relation with zonal winds}

The daily zonal mean zonal wind obtained from the UKMO stratospheric assimilated data is investigated during September 2008 to February 2009 to understand the dynamical effects of the KW in the lower and middle atmosphere and is shown in Fig. 8. Wind is plotted as a function of time and pressure, and the approximate altitudes are shown on the right. Below $\sim 10 \mathrm{mbar}$, the winds were moderate in strength with easterlies at the surface and westerlies above. During November 2008 to January 2009 the westerlies extended down up to 500 mbar. Above $\sim 20$ mbar, the winds were easterlies. Above $1 \mathrm{mbar}$, the winds were slowly descending westerlies up to early December 2008 and easterlies thereafter. It can be seen that around $\sim 35 \mathrm{~km}$, the magnitude of the easterlies reduced by $\sim 10 \mathrm{~m} \mathrm{~s}^{-1}$ during November to early December. At higher altitudes, $>52 \mathrm{~km}$, the magnitude 
Table 1. KW properties in the middle atmosphere from literature.

\begin{tabular}{|c|c|c|c|c|c|}
\hline $\begin{array}{l}\text { Period of } \\
\text { observations }\end{array}$ & $\begin{array}{l}\text { Mode of } \\
\text { observations }\end{array}$ & $\begin{array}{l}\text { Wave- } \\
\text { number }\end{array}$ & $\begin{array}{l}\text { Period } \\
\text { (days) }\end{array}$ & $\begin{array}{l}\text { Vertical } \\
\text { wavelength } \\
(\mathrm{km})\end{array}$ & Reference \\
\hline Dec 1965-May1966 & Radiosonde & - & 15 & - & Wallace and Kousky (1968) \\
\hline Oct 1978, Jan-Feb 1979 & Nimbus-7, LIMS & 1,2 & $4-9$ & $13-41$ & Salby et al. (1984) \\
\hline Oct 1978-May 1979 & LIMS & $1,2,3$ & $4-12$ & $13-42$ & Hitchman and Leovy (1988) \\
\hline $\begin{array}{c}\text { Dec 1991-Feb } 1992 \\
\text { \& Jul-Sep } 1992\end{array}$ & MLS/UARS & 1,2 & 4,8 & $14-44$ & Canziani et al. (1994) \\
\hline Jan 1992-May 1993 & CLAES/UARS & 1 & 14 & 10 & Shiotani et al. (1997) \\
\hline 17 Jun-15 Jul 1999 & Radiosonde & 2,4 & $5,9.5$ & $3-4.5$ & Holton et al. (2001) \\
\hline Jul 1992-Apr 1993 & MLS/UARS & 1,2 & $4.5-10$ & $14-23$ & Mote et al. (2002) \\
\hline May 2001-Oct 2005 & CHAMP (GPS RO) & & $10-15$ & $5-8$ & Venkat Ratnam et al. (2006) \\
\hline 10 Apr-9 May 2004 & Radiosonde, CHAMP (GPS RO) & 1,2 & $10-12$ & $6-7$ & Tsuda et al. (2006) \\
\hline 10 Apr-9 May 2004 & Radiosonde \& SABER/TIMED & 3 & 7 & $5.5-6.5$ & Sridharan et al. (2006) \\
\hline Aug 2006-Aug 2009 & F-3/C (GPS RO) & 1,2 & $6-15$ & - & Pan et al. (2011) \\
\hline Sep 2008-Feb 2009 & F-3/C (GPS RO) & 1,2 & $7.5-15$ & $12-18$ & Present study \\
\hline
\end{tabular}

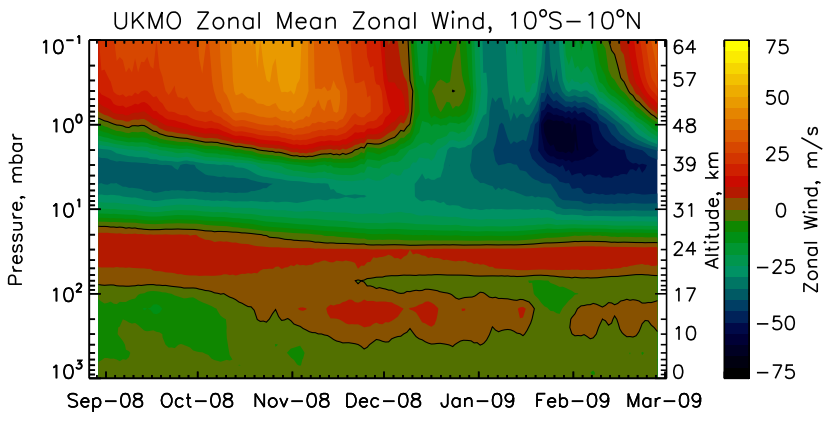

Fig. 8. UKMO daily zonal mean zonal wind during September 2008 to February 2009 averaged over $10^{\circ} \mathrm{S}-10^{\circ} \mathrm{N}$. Observe the decrease in the easterly wind during November and December at $26-40 \mathrm{~km}$.

of the easterlies was oscillating significantly, with amplitudes greater than $10 \mathrm{~m} \mathrm{~s}^{-1}$. Also note that the vertical extent of the westerly phase in the lower stratosphere is very thin during November 2008 to February 2009 compared to that during September 2008. The thinning of the westerly wind region during the latter period seems to be playing an important role in the effect of KW on the tropical zonal wind as will be discussed below.

The vertical propagation of the various $\mathrm{KW}$ with different wavelengths would depend on the mean zonal wind in the lower stratosphere. Interestingly, the vertical extent of the westerly wind regime, is varying significantly during September 2008 to February 2009. During P1, only the KW with larger vertical wavelengths would be allowed to propagate, while during P2 and P3 this threshold reduces to a lower level and $\mathrm{KW}$ of shorter vertical wavelengths also would propagate to higher altitudes. Figure 6 also shows that there is an altitude dependence of the dominant $\mathrm{KW}$ observed, which is different during the three periods of interest. During P1, the powers of the $\mathrm{KW}$ is moderate and are observed only up to about $26 \mathrm{~km}$, while during P2, the amplitudes are high up to about $26 \mathrm{~km}$ and reduce thereafter. The KW might be damped at these altitudes in the upper stratosphere, thereby depositing the energy and the momentum. On the other hand, during P3, the power of the KW (Fig. 6) is almost constant at all altitudes, showing no energy deposition of the wave. From all the above observations, we can summarise the findings during the three periods as follows.

1. During P1, the KW produced are of moderate amplitudes, among which only the large vertical wavelength waves are allowed to pass through the westerly wind regime in the lower stratosphere. They do not show any visible effect on the easterly zonal wind.

2. During $\mathrm{P} 2$, the $\mathrm{KW}$ activity is very strong and almost all the waves that are produced are allowed to pass through the thin westerly wind regime in the lower stratosphere. In the easterly wind region from $26-40 \mathrm{~km}$, the energy of the waves might have been deposited as they cannot propagate further into the westerly regime above $40 \mathrm{~km}$, thereby decreasing the westward wind at these altitudes of the upper stratosphere by as much as $10 \mathrm{~m} \mathrm{~s}^{-1}$.

3. During P3 also, the KW activity is strong and almost all the KW are allowed to pass through. However, these waves might have travelled to much higher altitudes as they do not encounter any shear zones and no energy is lost at least until $\sim 50 \mathrm{~km}$.

\subsection{Outgoing longwave radiation}

We also investigated the outgoing long wave radiation (OLR) as the probable cause for the generation of the observed $\mathrm{KW}$ for the sake of completeness. It is used as proxy for deep convection in the lower atmosphere, which is the dominating 


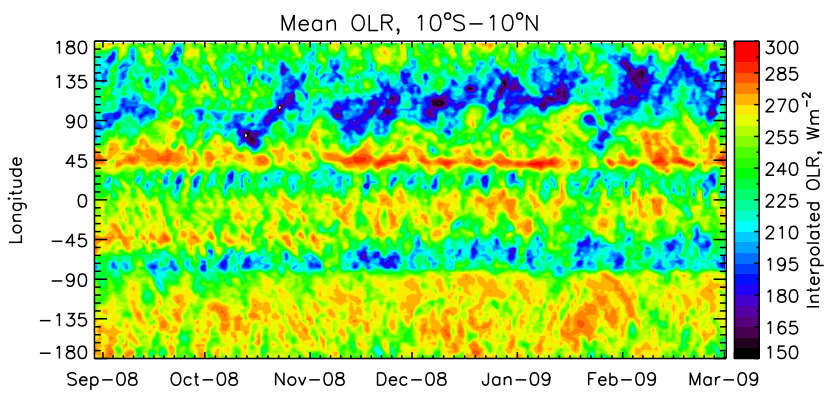

Fig. 9. Daily mean interpolated OLR averaged over $10^{\circ} \mathrm{S}-10^{\circ} \mathrm{N}$ latitudes during September 2008 to February 2009. Observe the low OLR at longitudes $60-180^{\circ}$.

source of a variety of waves with different spatial and temporal characteristics (Salby and Garcia, 1987). Figure 9 shows the daily mean OLR averaged over $10^{\circ} \mathrm{S}-10^{\circ} \mathrm{N}$ latitudes from September 2008 to February 2009, obtained from the daily gridded OLR data available with the NOAA Earth System Research Laboratory, Physical Sciences Division. The daily data are available on a $2.5^{\circ} \times 2.5^{\circ}$ latitude-longitude grid, with data gaps filled by linear interpolation to provide complete sampling. The figure shows that the OLR is quite low $\left(<210 \mathrm{~W} \mathrm{~m}^{-2}\right.$, blue region $)$ in the $60-180^{\circ}$ longitude region, i.e., over Indonesia, especially during P2 and P3, when we have observed strong $\mathrm{KW}$ activity and is an indication of tropical deep convections in the lower atmosphere. The low OLR regions are eastward propagating, but with phase speeds of $\sim 5 \mathrm{~m} \mathrm{~s}^{-1}$, which are much smaller than that of the observed KW $\left(\sim 30-40 \mathrm{~m} \mathrm{~s}^{-1}\right)$. This shows that the KW are not continuously coupled to the deep convections and are "free" modes that once produced by the convections, propagate vertically upward independently.

\subsection{Implications of the study}

KW properties investigated in the current study provide very interesting insights into the current understanding of the middle atmospheric dynamics. Many earlier studies showed that no KW were observed during the westerly phase of the zonal winds and the amplitudes were significantly enhanced during the descending westerly shear phase of the QBO (Randel and Wu, 2005; Venkat Ratnam et al., 2006; Pan et al., 2011, etc.). In the current study, however, we have observed strong KW activity during the westerly period of QBO and an easterly shear at around $25 \mathrm{~km}$. This seems to be a combined effect of the generation of the waves around the tropopause, large vertical wavelengths, thin westerly zone and subsequent upward propagation of the waves. This event shows short term effects on the zonal winds as the KW might have deposited energy below the next shear level and reduced the easterly wind magnitude in the upper stratosphere. Holton et al. (2001) also showed evidence for $\mathrm{KW}$ in radiosonde data when the QBO was in its westerly phase. However, the vertical wavelengths were short and their effect on the zonal winds in the upper stratosphere was not discussed.

As the easterly phase is building up in the upper stratosphere, one would expect a gradual increase in the easterly wind. However, the current KW episode seems to have affected the progress significantly. The investigation in the present study is only during one cycle, motivated from the results of Pan et al. (2011), where there are easterlies in the upper stratosphere and westerlies in the lower stratosphere and the vertical extent of the latter is small compared to the vertical wavelengths of the $\mathrm{KW}$ observed. It is possible that such a situation is not unique and might have occurred during other QBO cycles. This work will be continued in future to investigate such events, if any.

A broad spectrum of waves including a combination of Kelvin, Rossby-gravity, inertia-gravity and smaller-scale gravity waves provide most of the momentum flux needed to drive the QBO via a two-way feedback mechanism of the effect of background flow on the wave momentum fluxes and vice versa (Lindzen and Holton, 1968; Holton and Lindzen, 1972; Dunkerton, 1997). All these waves originate in the tropical troposphere due to deep convections. High frequency inertia-gravity and gravity waves provide a continuous source of momentum forming one of the major drivers of the QBO and eastward propagating Kelvin waves and westward propagating Rossby-gravity waves provide another major chunk of the momentum to drive the westerlies and easterlies, respectively (Baldwin et al., 2001). However, the actual contribution of each of the waves depending upon the mean background flow is still unclear. Many works in this direction have focused on a few cycles of the QBO (Ern et al., 2008; Ern and Preusse, 2009), and a generalised theory is yet to come. Definitive climatologies of the properties of KW and other vertically propagating waves of interest to the QBO are, thus, required. It is envisaged that the current study, though event-based and small, will contribute in this direction, as the event investigated is not unique and is definitely possible during other cycles also. It emphasises the short-term variations of the tropical zonal winds, which also are required to be investigated to understand the larger scale variations.

\section{Summary}

KW activity is investigated during September 2008 to February 2009 from FORMOSAT-3/COSMIC temperature data using the two-dimensional Fourier transform. 2D-FFT has been performed on temperature fluctuations that showed strong KW activity with high amplitudes at wavenumbers E1 and E2, with periods of 7.5 and 13 days and vertical wavelengths ranging from 12 to $18 \mathrm{~km}$. These $\mathrm{KW}$ are probably produced by the strong convective activity in the lower atmosphere, as observed in the very low daily mean OLR (averaged over $10^{\circ} \mathrm{S}-10^{\circ} \mathrm{N}$ latitudes), in the longitudes $60-180^{\circ}$. These waves propagated upward and might have affected the 
zonal winds, by decreasing the easterly wind in the upper stratosphere. This event is very intriguing as the QBO during this period was westerly in the lower stratosphere (up to $\sim 26 \mathrm{~km}$ ) and easterly above, whereas, climatological studies show that KW get attenuated during westerlies and their amplitudes maximise during easterlies and westerly shears. And the interesting result of this study is that these eastward propagating waves have not been damped by the westerly winds in the lower stratosphere due to longer vertical wavelengths of the former combined with the thin vertical extent of the latter.

Acknowledgements. The authors thank the UCAR/COSMIC programme for providing free access to the temperature data, United Kingdom Meteorological Office for the stratospheric assimilated data through the British Atmospheric Data Centre (BADC) and NOAA/OAR/ESRL PSD, Boulder, Colorado, USA, for the interpolated OLR data from their web site at http://www.esrl.noaa.gov/ psd/. S. S. Yang is acknowledged for his help and support. UD and CJP are supported by the NSC of Taiwan through grant NSC 1012111-M-008-011.

Topical Editor C. Jacobi thanks two anonymous referees for their help in evaluating this paper.

\section{References}

Alexander, S. P., Tsuda, T., Kawatani, Y., and Takahashi, M.: Global distribution of atmospheric waves in the equatorial upper troposphere and lower stratosphere: COSMIC observations of wave mean flow interactions, J. Geophys. Res., 113, D24115, doi:10.1029/2008JD010039, 2008.

Baldwin, M. P., Gray, L. J., Dunkerton, T. J., Hamilton, K., Haynes, P. H., Randel, W. J., Holton, J. R., Alexander, M. J., Hirota, I., Horinouchi, T., Jones, D. B. A., Kinnersley, J. S., Marquardt, C., Sato, K., and Takahashi, M.: The Quasi-Biennial Oscilaltion., Rev. Geophys., 39, 179-229, doi:10.1029/1999RG000073, 2001.

Canziani, P. O. and Holton, J. R.: Kelvin Waves and the quasibiennial oscillation: An observational Analysis, J. Geophys. Res., 103, 31509-31521, 1998.

Canziani, P. O., Holton, J. R., Fishben, E., Froidevaux, L., and Waters, J. W.: Equatorial Kelvin Waves: A UARS MLS View, J. Atmos. Sci., 51, 3053-3076, 1994.

Chang, L. C., Palo, S. E., Liu, H.-L., Fang, T.-W., and Lin, C. S.: Response of the thermosphere and ionosphere to an ultra fast Kelvin wave, J. Geophys. Res., 115, A00G04, doi:10.1029/2010JA015453, 2010.

Dunkerton, T. J.: The role of gravity waves in the quasi-biennial oscillation, J. Geophys. Res., 102, 26053-26076, 1997.

Ern, M. and Preusse, P.: Quantification of the contribution of equatorial Kelvin waves to the QBO wind reversal in the stratosphere, Geophys. Res. Lett., 36, L21801, doi:10.1029/2009GL040493, 2009.

Ern, M., Preusse, P., Krebsbach, M., Mlynczak, M. G., and Russell III, J. M.: Equatorial wave analysis from SABER and ECMWF temperatures, Atmos. Chem. Phys., 8, 845-869, doi:10.5194/acp-8-845-2008, 2008.
Fong, C. J., Yen, N. L., Chu, C. H., Yang, S. K., Shiau, W. T., Huang, C. Y., Chi, S., Chen, S. S., Liou, Y. A., and Kuo, Y. H.: FORMOSAT-3/COSMIC Spacecraft Constellation System, Mission Results, and Prospect for Follow-On Mission, Terr. Atmos. Ocean. Sci., 20, 1-19, doi:10.3319/TAO.2008.01.03.01(F3C), 2009.

Forbes, J. M.: Wave coupling between the lower and upper atmosphere: case study of an ultra-fast Kelvin Wave, J. Atmos. Sol. Terr. Phys., 62, 1603-1621, 2000.

Forbes, J. M., Zhang, X., Palo, S. E., Russell, J., Mertens, C. J., and Mlynczak, M. G.: Kelvin waves in stratosphere, mesosphere and lower thermosphere temperatures as observed by TIMED/SABER during 2002-2006, Earth Planets Space, 61, 447-453, 2009.

Fueglistaler, S., Dessler, A. E., Dunkerton, T. J., Folkins, I., Fu, Q., and Mote, P. W.: Tropical tropopause layer, Rev. Geophys., 47, RG1004, doi:10.1029/2008RG000267, 2009.

Fujiwara, M., Kita, K., and Ogawa, T.: Stratosphere-troposphere exchange of ozone associated with the equatorial Kelvin wave as observed with ozonesondes and rawinsondes, J. Geophys. Res., 103, 19173-19182, doi:10.1029/98JD01419, 1998.

Hayashi, Y.: Space-Time Spectral Analysis and its Applications to Atmospheric Waves, J. Meteor. Soc. Japan, 60, 156-171, 1982.

Hayashi, H., Furumoto, J.-I., Lin, X., Tsuda, T., Shoji, Y., Aoyama, Y., and Murayama, Y.: Validation of Refractivity Profiles Retrieved from FORMOSAT-3/COSMIC Radio Occultation Soundings: Preliminary Results of Statistical Comparisons Utilizing Balloon-Borne Observations, Terr. Atmos. Ocean. Sci., 20, 51-58, 2009.

Hirota, I.: Equatorial waves in the upper stratosphere and mesosphere in relation to the semiannual oscillation on the zonal wind, J. Atmos. Sci., 35, 714-722, 1978.

Hirota, I.: Kelvin waves in the equatorial middle atmosphere observed by the Nimbus 5 SCR, J. Atmos. Sci., 36, 217-222, 1979.

Hitchman, M. H. and Leovy, C. B.: Estimation of the Kelvin Wave Contribution to the Semiannual Oscillation, J. Atmos. Sci., 45, 1462-1475, 1988.

Holton, J. R. and Lindzen, R. D.: A Note on "Kelvin" Waves in the Atmosphere, Mon. Weather Rev., 96, 385-386, 1968.

Holton, J. R. and Lindzen, R. S.: An updated theory for the quasibiennial cycle of the tropical stratosphere, J. Atmos. Sci., 29, 1076-1080, 1972.

Holton, J. R., Alexander, M. J., and Boehm, M. T.: Evidence for short vertical wavelength Kelvin waves in the Department of Energy - Atmospheric Radiation Measurement Nauru99 radiosonde data, J. Geophys. Res, 106, 20125-20129, 2001.

Kawatani, Y., Takahashi, M., Sato, K., Alexander, S. P., and Tsuda, T.: Global distribution of atmospheric waves in the equatorial upper troposphere and lower stratosphere: AGCM simulation of sources and propagation, J. Geophys. Res., 114, D01102, doi:10.1029/2008JD010374, 2009.

Kawatani, Y., Watanabe, S., Sato, K., Dunkerton, T. J., Miyahara, S., and Takahashi, M.: The Roles of Equatorial Trapped Waves and Internal Inertia-Gravity Waves in Driving the Quasi-Biennial Oscillation. Part I: Zonal Mean Wave Forcing, J. Atmos. Sci., 67, 963-980, 2010.

Kishore, P., Namboothiri, S. P., Jiang, J. H., Sivakumar, V., and Igarashi, K.: Global temperature estimates in the troposphere and stratosphere: a validation study of 
COSMIC/FORMOSAT-3 measurements, Atmos. Chem. Phys., 9, 897-908, doi:10.5194/acp-9-897-2009, 2009.

Lieberman, R. S. and Riggin, D.: High resolution Doppler imager observations of Kelvin waves in the equatorial mesosphere and lower thermosphere, J. Geophys. Res., 102, 26117-26130, 1997.

Lindzen, R. D. and Holton, J. R.: A Theory of the Quasi-Biennial Oscillation, J. Atmos. Sci., 25, 1095-1107, 1968.

Matsuno, T.: Quasi-Geostrophic Motions in the Equatorial Area, J. Meteor. Soc. Japan, 44, 25-43, 1966.

Mote, P. W., Dunkerton, T. J., and Wu, D.: Kelvin waves in stratospheric temperature observed by the Microwave Limb Sounder, J. Geophys. Res., 107, 4218, doi:10.1029/2001JD001056, 2002.

Pan, C. J., Das, U., Yang, S., J. Wong, C., and Lai, C. H.: Investigation of Kelvin Waves in the Stratosphere Using FORMOSAT3/COSMIC Temperature Data, J. Meteor. Soc. Japan, 89A, 8396, 2011.

Randel, W. J. and Wu, F.: Kelvin wave variability near the equatorial tropopause observed in GPS radiosonde occultation measurements, J. Geophys. Res., 110, D03102, doi:10.1029/2004JD005006, 2005.

Rao, D. N., Venkat Ratnam, M., Mehta, S. K., Nath, D., Basha, G., Rao, V. V. M. J., Krishna Murthy, B. V., Tsuda, T., and Nakamura, K.: Validation of the COSMIC Radio Occultation Data over Gadanki $\left(13.48^{\circ} \mathrm{N}, 79.2^{\circ} \mathrm{E}\right)$ : A Tropical Region, Terr. Atmos. Ocean. Sci., 20, 59-70, 2009.

Salby, M. L. and Garcia, R. R.: Transient Response to Localised Episodic Heating in the Tropics. Past I: Excitation and ShortTime Near-Field Behaviour, J. Atmos. Sci., 44, 458-498, 1987.

Salby, M. L., Hartmann, D. L., Bailey, P. L., and Gille, J. C.: Evidence for Equatorial Kelvin Waves in Nimbus-7 LIMS, J. Atmos. Sci., 41, 220-235, 1984.

Shiotani, M. and Horinouchi, T.: Kelvin Wave Activity and the Quasi-Biennial Oscillation in the Equatorial Lower Stratosphere, J. Meteor. Soc. Japan, 71, 175-182, 1993.

Shiotani, M., Gille, J. C., and Roche, A. E.: Kelvin Waves in the equatorial lower stratosphere as revealed by cryogenic limb array etalon spectrometer temperature data, J. Geophys. Res., 102, 26131-26140, 1997.

Sridharan, S., Tsuda, T., Nakamura, T., Kozu, T., Mori, S., and Russell, J. M.: Observations of the 7-day Kelvin Wave in the Tropical Atmosphere During the CPEA Campaign, J. Meteor. Soc. Japan, 84A, 259-275, 2006.
Suzuki, J., Shiotani, M., and Nishi, N.: Lifetime and longitudinal variability of equatorial Kelvin waves around the tropical tropopause region, J. Geophys. Res., 115, D03103, doi:10.1029/2009JD012261, 2010.

Takahashi, H., Wrasse, C. M., Fechine, J., Pancheva, D., Abdu, M. A., Batista, I. S., Lima, L. M., Batista, P. P., Clemesha, B. R., Schuch, N. J., Shiokawa, K., Gobbi, D., Mlynczak, M. G., and Russell, J. M.: Signatures of ultra fast Kelvin waves in the equatorial middle atmosphere and ionosphere, Geophys. Res. Lett., 34, L11108, doi:10.1029/2007GL029612, 2007.

Tsai, H.-F., Tsuda, T., Hajj, G. A., Wickert, J., and Aoyama, Y.: Equatorial Kelvin Waves Observed with GPS Occultation Measurements (CHAMP and SAC-C), J. Meteor. Soc. Japan, 82, 397-406, 2004.

Tsuda, T., Murayama, Y., Wiryosumarto, H., Harijono, S. W. B., and Kato, S.: Radiosonde observations of equatorial atmosphere dynamics over Indonesia 1. Equatorial waves and diurnal tides, J. Geophys. Res., 99, 10491-10505, 1994.

Tsuda, T., Yoshida, S., Isoda, F., Nakamura, T., Nuryanto, A., Manurung, S., Sobari, O., Vincent, R. A., and Reid, I. M.: Long-term variations of atmospheric wave activity in the mesosphere and lower thermosphere region over the equatorial Pacific, J. Atmos. Sol. Terr. Phys., 64, 1123-1129, 2002.

Tsuda, T., Ratnam, M. V., Kozu, T., and Mori, S.: Characteristics of 10-day Kelvin wave observed with radiosondes and CHAMP/GPS occultation during the CPEA campaign (AprilMay, 2004), J. Meteor. Soc. Japan, 84A, 277-293, 2006.

Venkat Ratnam, M., Tsuda, T., Kozu, T., and Mori, S.: Longterm behavior of the Kelvin waves revealed by CHAMP/GPS RO measurements and their effects on the tropopause structure, Ann. Geophys., 24, 1355-1366, doi:10.5194/angeo-24-13552006, 2006.

Wallace, J. M. and Kousky, V. E.: Observational Evidence of Kelvin Waves in the Tropical Stratosphere, J. Atmos. Sci., 25, 900-907, 1968.

Wheeler, M. and Kiladis, G. N.: Convectively Coupled Equatorial Waves: Analysis of Clouds and Temperature in the WavenumberFrequency Domain, J. Atmos. Sci., 56, 374-399, 1999. 